\title{
Aprendizagem Cooperativa em Ambientes Telemáticos
}

\author{
Ana Vilma Tijiboy' \\ Débora Laurino Maçada ${ }^{2}$ \\ Lucila Maria Costi Santarosa ${ }^{3}$ \\ Léa da Cruz Fagundes ${ }^{4}$
}

\begin{abstract}
Aesumo: Esse trabalho enfatiza a importanciz da aprendizacem cooperativa em ambientes

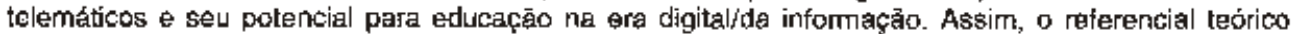
inclui autures que ressaltam a importancla da copperaçăo ha aprendizagem e no desenwolvirnento do sujeito. Sâo apresentados como elamentos relevantes que suportam e propiciarr a aprendizagem cooperativa ne Intemet, a postura cooperativa, a estrutura do ambiente e a funcionamento heterárquico do megmo.
\end{abstract}

Palavras-chave: cooperaçăo, colaboraçă, interaçäo.

Abstract: The focus of this papor are telematic cooperative leaming enwironments and their potential in education In the present digltalinfomation era. Thus, the theoretical framework ineludes authors who highlight the relevance of copperation in learning and development of the Individuals. A cooperative attitude, the structure of the telematic environment and a non-hierarchical functioning of such environment are presented as relowant elements for a cooperative learring to take place.

Key-words: cooperation, colaboration: interaction.

\section{Introduçāo}

$\dot{E}$ inquestionável que atualmente presencia-se um importante momento histórico, revolucionado pelos grandes avanços dos meios de comunicação e da informática. Ambos, unidos, potencializam ainda mais os seus impactos sobre diversos aspectos da atividade humana, dentre eles os relacionados a educaçâo.

Entre os impactos mais importantes pode-se destacar: a forna de comunicaçăo entre as pessoas; 0 surgimento do pensar inferencial indo além do indutivo e dedutivo; a diversificaçăo na repreşentaçăo do pensamento através dos meio multimídias aliados à telemática; uma nova concepçăo de espaço e tempo no sentido de derrubar fronteiras de comunicaçäo.

A sociedade atual caracteriza-șe pela grande quantidade de informaçäo existente (ULINE, 1996) pelo fácil acesso a ela por parte dos que possuem e dominam os recursos tecnológicos e telemáticos e também pela constante e rápida mudança da informação.

A economia globalizada, por sua vez, exige uma māo-de-obra com uma qualificação qualitativamente diferenciada do passado. Așsim, a familiarizaçāo com novas tecnologias da informaçāo e a constante e continua atualização profissional por parte dos trabalhadores serão necessárlas (FELLLERS, 1997).

E frente a esta nova realidade em radical transformaçăo que a educaçäo deve refletir sobre seu papel e propor novos rumos, de forma a vir ao encontro năo só das exigências do mercado de trabalho onde os alunos serāo inseridos mas também, e principalmente, de como promover o desenvolvimento de cidadãos críticos, autônomos, criativos, que solucionem problemas em contextos imprevistos, que questionem e transformem sua própria sociedade, em suma, sujeitos de seu próprio ambiente.

Doutoranda em Infomática na Eduçaçä́ (UFFGS), Mestre em Educaçăo (Stantord Univerṣity), Cọordẹnatora do Núcheo de

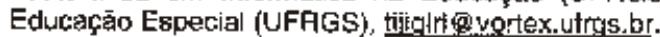

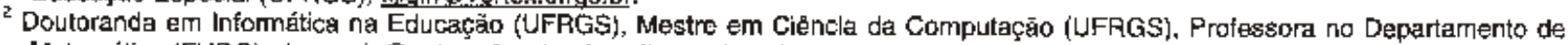

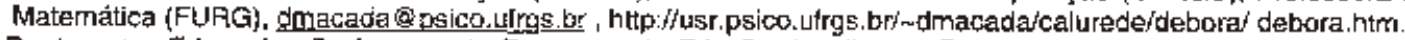

3 Doutora em Educaça. Professora do Programa de Pos-Graduaca em Educaça a do Doutorado em Intomatica na Educacáa

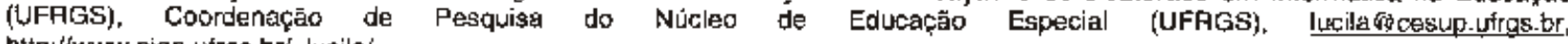
http://www. niee ufrgs.br/n |ucila/.

- Doutora em Psicologia, Professora do Curso de Pós-Graduaçăo em Psicologia do Desenvolvimento, do Curso de Pós-Graduaçóo em Psicologia Social e Inșituc|onal e do Doutorado em Intomática na Educaçāo (UFRGS) Coordenadora Cientilica do LEC (UFRGS) legtagung vortex, utrgs, br 
Este trabalho pretende provocar uma reflexăo sobre porque cooperaçáo e colaboração sāo importantes no processo de aprendizagem e desenvolvimento para formar o cidadăo que atuará nessa sociedade e como viabilizá-las em ambientes telemáticos.

Para tanto, são apresentadas algumas consideraçōes a respeito da mudança de paradigma no que se refere a educaçāo seguidas de conceitos e concepçöes sobre interaçăo, colaboraçāo cooperaçăo; posteriormente săo colocadas algumas consideraçóes sobro ambientes cooperativos a distancia; finalmente säo resseltados elementos importantes para a aprendizagem em ambientes teleméticos cooperativos a tecidas algumas consideraçües.

\section{Interação, Colaboraçăo e Cooperaçāo}

Existe por parte da sociedade uma preccupaçảo sobre os rumos da educaçăo no momento atual. Reflexóes a este respeito apontam para mudanças substanciais no que diz respeito ao conhecimento, as relaçóes pntre os envolvidos, ao contexto educacional, às concepcōes do que é ensinar, ao papel da escola, do professor e do aluno.

Na tentativa de melhor compreender esses novos rumos apresenta-se na tabela abaixo, baseada em FELLERS (1996), algumas características do antigo e do novo paradigma educacional.

Tabela 1: Paradigma Antigo $x$ Paradigma Novo

\begin{tabular}{|c|c|c|}
\hline & $\begin{array}{l}\text { Paradigma antigo } \\
\text { (Era Industrlal) }\end{array}$ & $\begin{array}{l}\text { Paradigma novo } \\
\text { (Era Digital/da Informaçäo) }\end{array}$ \\
\hline Conhecimento & $\begin{array}{l}\text { Tramsmissão do professor para o } \\
\text { aluno }\end{array}$ & $\begin{array}{l}\text { Gonstrução coletiva pelos } \\
\text { estudantes e professor }\end{array}$ \\
\hline Estudantes & $\begin{array}{l}\text { Passivos, "caixas vazias a } \\
\text { serem" preenchidas pelo } \\
\text { conhecimento do professor. } \\
\text { Recebem ordens }\end{array}$ & $\begin{array}{l}\text { Ativos, construtores, } \\
\text { descobridores transformadores do } \\
\text { conhecimento. } \\
\text { Tomam decisōes }\end{array}$ \\
\hline $\begin{array}{l}\text { Objetivo do } \\
\text { professor }\end{array}$ & Classificar e selecionar os alunos & $\begin{array}{l}\text { Desenvolver os talentos dos } \\
\text { alunos }\end{array}$ \\
\hline Relaçöes & $\begin{array}{l}\text { Impessoal entre estudantes a } \\
\text { entre profes sor e estudante }\end{array}$ & $\begin{array}{l}\text { Pessoal entre os estudante e entre } \\
\text { protessor e estudantes }\end{array}$ \\
\hline Contexto & $\begin{array}{l}\text { Aprendizagem competitiva, } \\
\text { individualista. } \\
\text { Informaçäo limitada }\end{array}$ & $\begin{array}{l}\text { Aprendizagem cooperativa e } \\
\text { equipes cooperativas } \\
\text { professores, infinidade } \\
\text { informaçá de }\end{array}$ \\
\hline $\begin{array}{l}\text { Concepgäo de } \\
\text { educador } \\
\text { (pressupostos) }\end{array}$ & Qualquer um pode ensinar & $\begin{array}{l}\text { Ensinar é complexo e requer } \\
\text { considerável formaçăo }\end{array}$ \\
\hline
\end{tabular}

THORNBURG (1997), por sua vez, acredita que hoje em dia além da expressão verbal e escrita e do raciocinio matemático (habilidades tradicionalmente conşideradas essenciais), se faz necessário 0 desenvolvimento de novas habilidades ou talentos que incluem a fluencia tecnologica, a capacidade de resolver problemas e os "3 C's"- Comunicação, Colaboraçấo e Crlatividade.

Percebe-se através das colocaçōes acima uma forte ênfase na importância da interaçăo social, da colaboraçäo e da cooperaçăo no processo de aprendizagem/desenvolvimento. Mas, o que fundamenta esta ênfase?

O processo de interaçăo entre indivíduos possibilita intercambiar pontos de vistas, conhecer e refletir sobre diferentes questionamentos, refletir sobre seu próprio pensar, ampliar com autonomía sua tomada de consciencia para buscar novos rumos.

A importância da interaçăo é percebida por ECHEITA e MARTIN (1995) no sentido que "... conhecimento é gerado, construído ou melhor dito, co-construído, construido conjuntamente, exatamente porque se produz interatividade entre duas ou mais pessoas que participam dela" (Pág 37). Esta interaçäo social ou interpessoal é percebida como aspecto fundamental tanto pela epistemologia genética quanto pela escola sócio-histórica, cujos representantes majs significativos săo Piaget e Vygotsky (CLERMONTPERRET, 1992). 
Especificamente falando da interação social em rede de computadores podemos diferenciar nessa interação pelo menos dois aspectos: quanto a temporalidade e quanto ao direcionamento e número de interlocutores. Quanto à temporalidade tem-se interações síncrona (Figura 1) e assincrona (Figura 2). Quanto ao direcionamento e nümero de interlocutores as interaçōes podem ser do tipo: um-para-um (Figura 3) urm-para-todos (Figura 4), todos-para-todos (Figura 5).

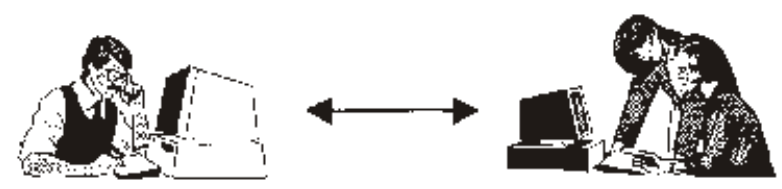

Figura 1- interação sincrona.

A interaçāo ocorre em tempo real, isto é, os interlocutores encontram-se ligados simultanearnente em rede e utilizam recursos que permitem aos envolvidos acompanharem o que o(s) outro(s) deseja(m) comunicar.

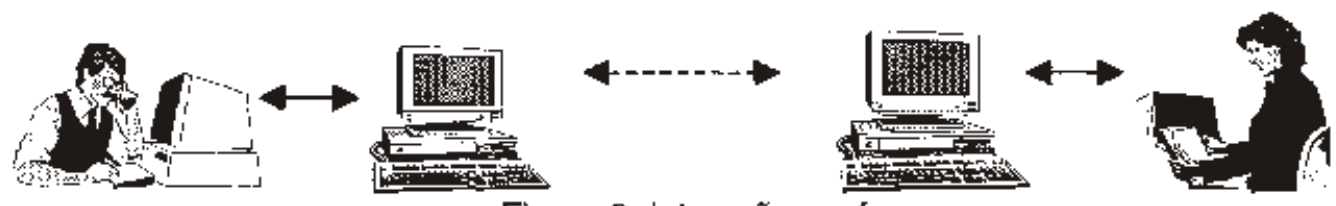

Figura 2- Lnteraçăo assíncrona.

Os interlocutores se comunicam sem estabelecerem ligaçăo direta. A interaçáo năo é intermediada por recursos que permitern aos interlocutores acompanharem o que o(s) outro(s) deseja(m) comunicar no momento exato em que a comunicaçāo é emitida. Podem ou năo os usuários estarem ligados em rede simultaneamente.

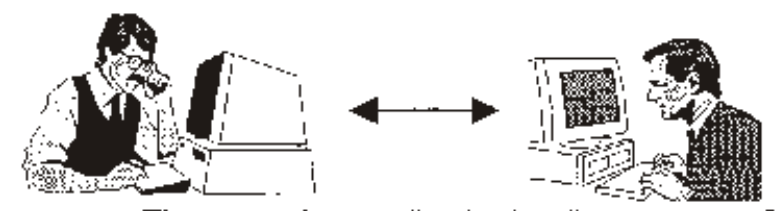

Figura 3 - Interaçẫo do tipo "um para um"

A comunicaçăo ocorre apenas entre dois individuos, podendo ser síncrona ou assíncrona.

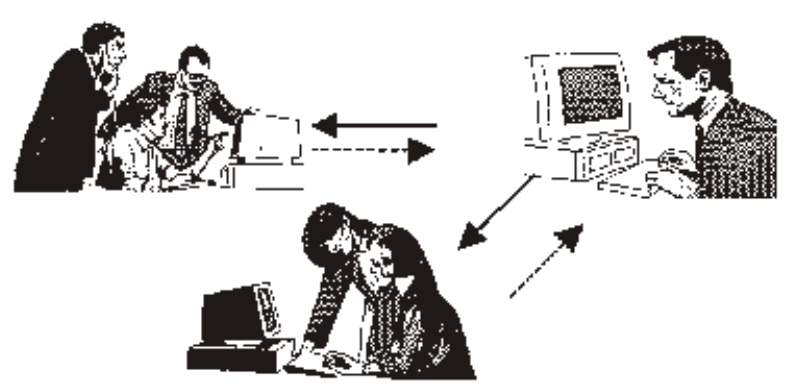

Figura 4 - Interação do tipo "um para todos"

Um usuário se comunica com vários receptores os quais podem também se tornar emissores, comunicandose com quem iniciou a interaçăo. Esta comunicaçāo pode ser síncrona ou assincrona.

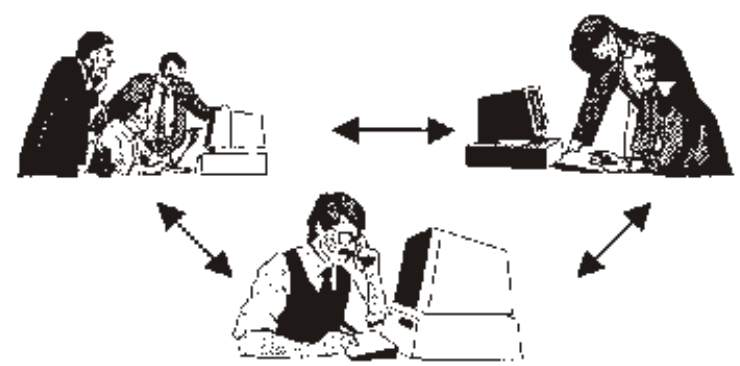

Figura 5 - Interaçäo do tipo 'todos para todos".

Comunicação entre múltiplos usuários, aqui todos interagem entre si, podendo ocorrer de forma síncrona ou assíncrona. 
A interação entre pessoas pode apenas ser eventual, isolada, e interrompida. Mas pode também possibilitar uma relaçāo colaborativa ou cooperativa, que pressupõe alguns requisitos que vão além da mera interaçăăo.

A fim de ressaltar importancia de trabalhos colaborativos e cooperativos aborda-se a seguir conceitos e concepçöes encontrados na literatura. Alguns autores definem ou se referem a cooperaçào e colaboraçâo como sinônimos, outros porém, fazem distinçăo.

FERREIRA (1986, apud BARROS 1994) define colaboraçāo como "trabalho em comum com uma ou mais pesscas; cooperaçăo; auxílio; contribuiçāo" (pag 38). KAYE (1991, apud BARROS ,1994): coloca que:

"...colaborar (co-labore) significa trabalhar junto, que implica no conceito de objetivos compartilhados e uma intenção explicita de somar algo - criar alguma coisa nova ou diferente através da colaboração, se contrapondo a uma simples troca de informação ou passar instruçöes. " (pag 20).

Camo podemos observar, ambos autores não fazem distinçăo entré colaboração e cooperação.

BARAOS (1994) define colaboração como estando relacionada com contribuição. A cooperaçăo, por sua vez, é um trabalho de co-realizaçăo que alêm de atingir o significado de colaboraçāo, envolve o trabalho coletivo visando alcançar um objetivo comum. Estes dois conceitos para Barros săo distintos. $\mathrm{O}$ conceito de cooperaçăo é mais complexo na medida em que a colaboraçáo esté incluída nele, mas o contrário não se aplica. Essa complexidade de cooperação pode ser melhor compreendida através da concepçäo piagetiana.

Para PIAGET (1973 apud COSTA 1995; RAMOS, 1996) cooperaçăo é definida como co-operaçăo, isto é, cooperar na açăo é operar em comum; se caracteriza quando da coordenaçăo de pontos de vista diferentes, pelas operaçōes de correspondência, reciprocidade ou complementaridade e pela existéncia de regras autônomas de condułas fundamentadas no respeito mútuo. Ainda para Plaget, para que haja uma cooperaçāo real săo necessárias es seguintes condições: existência de uma escala comumn de valores; conservaçăo da escala de valores e existência de uma reciprocidade na interaçăo.

Para WGOTSKY (19B7) a colaboraçăo entre pares ajuda a desenvolver estratégjas e habilidades gerais de soluçăo de problemas pelo processo cognitivo implícito na interaçâo e na comunicação. Para o autor a linguagem é fundamental na estruturação do pensamento, sendo necessário para comunicar o conhecimento, as idéias do indivíduo e para entender o pensamento do outro envolvido na discussāo ou na conversaçáo. O trabalho em colaboraçăo com o outro, segundo esta teoria, enfatiza a ZDP - zona de desenvolvimento proximal - que é "algo coletivo" porque transcende os limites dos individuos.

O posicionamento das autoras, levando em consideração a revisão de literatura acima apresentada, é que o conceito de cooperaçăo é mais complexo, pois pressupōe a interaçăo e a colaboraçäo, alén de relaçōes de respeito mútuo e näo hierárquicas entre os envolvidos, uma postura de tolerância e convivôncia com as diferenças e um processo de negociação constante. Percebemos que a diferença fundamental entre ambos conceitos reside no fato de que para haver colaboraçå um individuo deve interagir com o outro, existindo ajuda - mútua ou unilateral. Para existir cooperação deve haver, interação, colaboração, mas também objetivos comuns, atividades e açōes conjuntas e coordenadas.

\section{Amblentes de Aprendizagem Cooperativos à Distância}

A telemática está revolucionando os conceitos de tempo e espaço na comunicaçāo entre as pessoas, no acesso a informação, na produçăo e na construçăo do conhecimento. É a intemet, dentre os recursos telemáticos, que pode propiciar a criaçăo de ambientes ricos, motivadores, interativos, colaborativos, cooperativos e de comunicação síncrona e assfincrona rápida e de custo relativamente baixo.

No entanto, percebe-se que a Internet tem sido predominantemente utilizada como um canal de transmissāo de informação, indicando assim uma subutilizaçāo deste meio. Acredita-se que uma utilização mais significativa, deva incluir conceitos e atitudes do tipo: interação, troca, intercåmbio, comtunicação bi ou multi-lateral, negociaçăo, colaboraçāo e cooperaçăo. Reforçando esta idéia RIEL (1997) diz que a Internet năo deve ser mais pensada como um "Iugar" ou como uma "highway", uma rodovia mas sim como lugar onde pode-se criar novos delineamentos sociais. Uma comunidade, urma construção entre pessoas que partilhem metas, valores e práticas comuns. 
A Educẹçăo à Distáncia ganha novo impulso levando a mudança do paradigma "diretivo/inear" para o "interativo/construtivo". Segundo SCHRUM (1997), a EAD representa um passo a frente rumo à educaçăo continuada, ao compartilhamento de informaçāo e ao trabalho cooperativo, pois permite uma continua especializaçă. A tecnologia pode apoiar estes objetivos com redes interativas e groupware, que permitem discussōes sfncronas e assincronas, atividades colaborativas e tomadas de decisoes em grupo. Mas em concordânçia com RIEL (1997) acredita-se que para uma eduçậa com mais ganhos qualitativos nāo basta apenas a criação de ambientes "fissicos/virtuaig" que reunam recursos de interaçăo humane mas também a construçäo de "combridades virtuais", "sociedades virtuais". Esta idéla contempla a concepçāo do espaço cibernético livre a ser habitado construindo aldeais ou comuridades de diversos tipos, portanto um ambiente onde as pessoas não sejam objetos e sim sujeitos construtores do mesmo.

\section{Elementos Relevantes para Aprendizagem Cooperativa em Ambientes Telemáticos}

Com base na literatura consultada sobre "aprendizagem colaborativa online", que se constitui em um fenomeno emergente, são focalizadas a seguir algumas consideraçōes relevantes, visando circunscrever esse contexto e o significado das relaçöes existentes, sem, contudo, ter-se a pretensāo de esgotar o assunto. O proposito é o de dar infcio ao processo de construçăo dos elementos essenciais que embasam ambientes de aprendizagem cooperativos em redes telemáticas.

Propöem-se pelo menos três elementos como essenciais, sem os quais acredita-se nāo ser possivel a viabilizaçāo de tais ambientes. Säo eles: (a) Postura cooperativa, (b) Estrutura do Ambiente e (c) Funcionamento Hețerárquico.

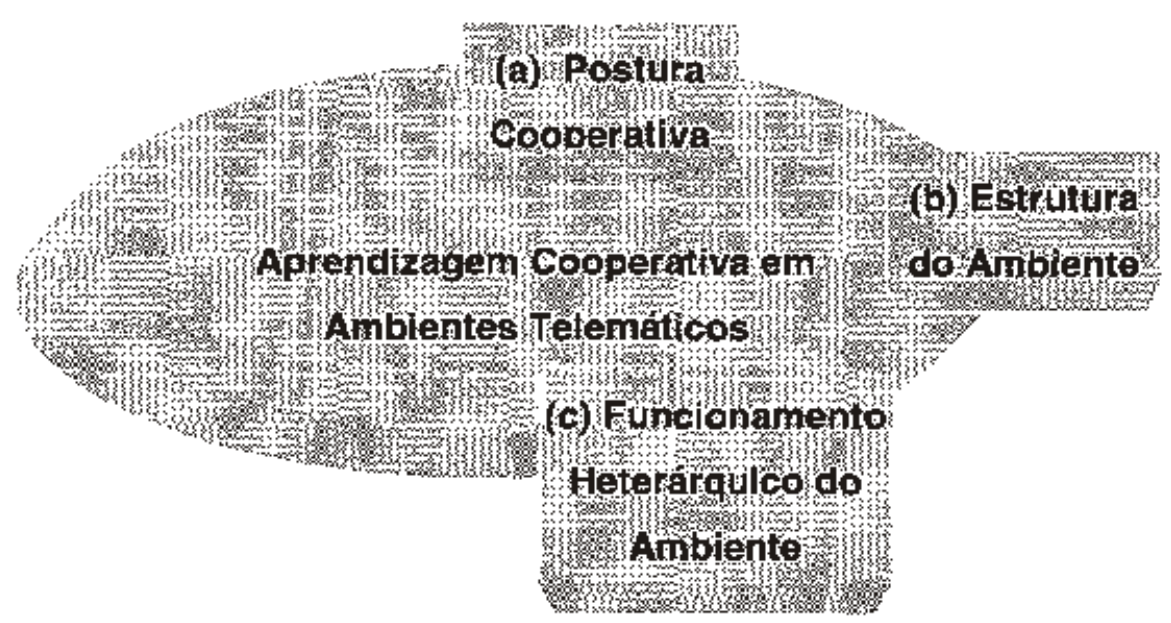

Figura 6: Aprendizagem em Ambientes Cooperativos na Internet

Cada um desses trés elementos săo detalhados a seguir:

a. Postura Cooperativa: acredita-se ser este o elemento mais importante para possibilitar a aprendizagem cooperativa na Internet. Algumas atitudes/aspectos explicitados e relacionados na figura a seguir fazem parte dessa postura que promove o desenvolvimento de tais atitudes. As flechas de dupla viè () mostrąm esta relaçāo dinâmica e dialética.

A figura acima mostra alguns dos elementos que constiłuem a postura copperativa, todo eles sāo fundamentais, porém a interação ("interaçăo") é o elemento básico e inicial de todo o processo pois é ela que abre o canal de comunicação. Mas ela também está e deve estar presente ao longo de todo o trabalho em grupo possibilitando uma negociaçăo constante entre os sujeitos envolvidos. 


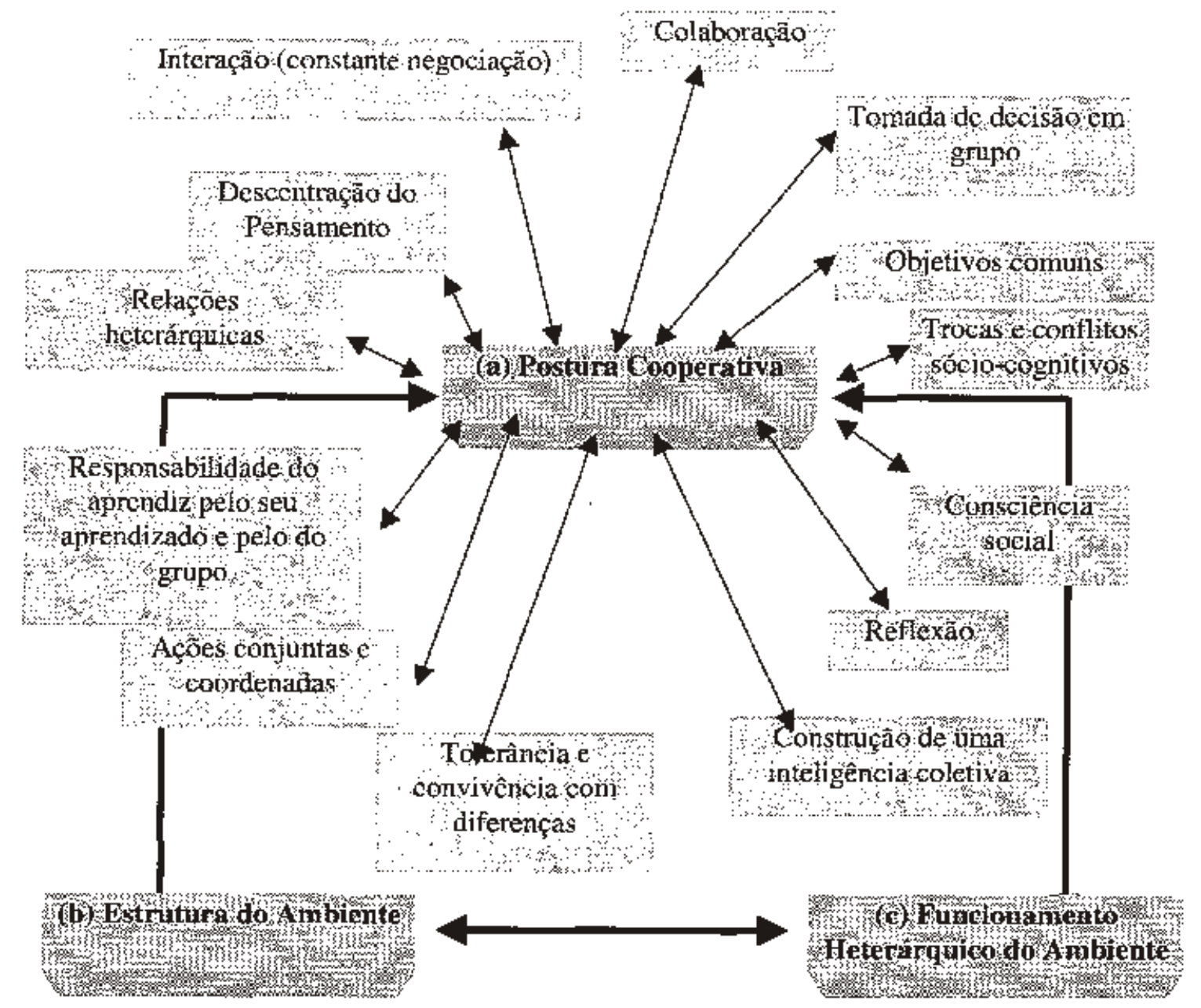

Figura 7: Postura Cooperativa

As relaçóes entre os sujeitos com postura cooperativa săo do tipo heterárquicas, o que permite tomada de decisāo em grupo de forma consensual, não imposta de cima para abaixo ou de um(s) sobre o(s) outro(s). Estas relą̧ões heterárquicas promovern uma consciência social onde estäo presentes a toleräncia e convivêncla com as diferenças.

Por sua vez, e somente a partir dos elementos acima é que os sujeitos se sentem parte importante - ativa do processo e passam a assumir uma postura de responsabilidade com relaçăo a sua própria aprendizagem e a do grupo. Assim, surgem as colaboraçōes individuais dando início ao processo de cooperaçāo a fim de alcançar os objetivos comuns estabelecidos pelo grupo.

As trocas sócio-cognitivas ocorrem através da interaçăo e colaboração entre os participantes e envolvem o compartilhamento de idéias, propostas, informaçóes, dúvidas e questionamentos. Nestas trocas, o sujeito confronta seu ponto de vista com o do outro descentrando o seu pensamento que poderả provocar reflexão e conflitos sócio-cognitivos. Estes últimos dizem respeito à capacidade de entender, respeitar as diferenças e fazer relaçöes, provocando inicialmente um desequilibrio essencial para que ocorra uma reestruturaçăo do pensamento.

O papel do conflito sócio-cognitivo na construçăo cognitiva fai evidenciada pela psicologia social genética. Um conflito, nessa perspectiva, só será possivel de ocorrer nas interaçöes onde existam sistemas de centraçōes cognitivas opostas. (Garnier, Bednarz e Vlanovskaya, 1996)

Agindo de forma conjunta e coordenada è possivel construir uma "Inteligéncía Coletiva", que é muito mais do que apenas a soma das contribuiçōes individuais, é um todo coletivo construido a reconstruído, elaborado e reelaborado, partilhado e compartilhado, o que certemente é mais enriquecedor para o grupo e também para a indivlduo. 
b. Estrutura do Ambiente: este elemento dá suporte prático para que ocorra a aprendizagem cooperativa em redes telemáticas, devendo ficar claro porém que ele é necessário nesse contexto, embora náo suficiente. A evólução da techologia faz com que os recursos que compōem a estrutura de um ambiente copperativo para aprendizagem à distancia sofram alteraçōes e acréscimos dovido aos avanços tecnológicos que ocorrem de foma répida e dinâmica.

De acordo com o que se dispbe atualmente pode-se dizer que os recursos e suas formas de utilizaçāo apresentados no gráfico abaixo sāo importantes para auxiliar o processo cooperativo.

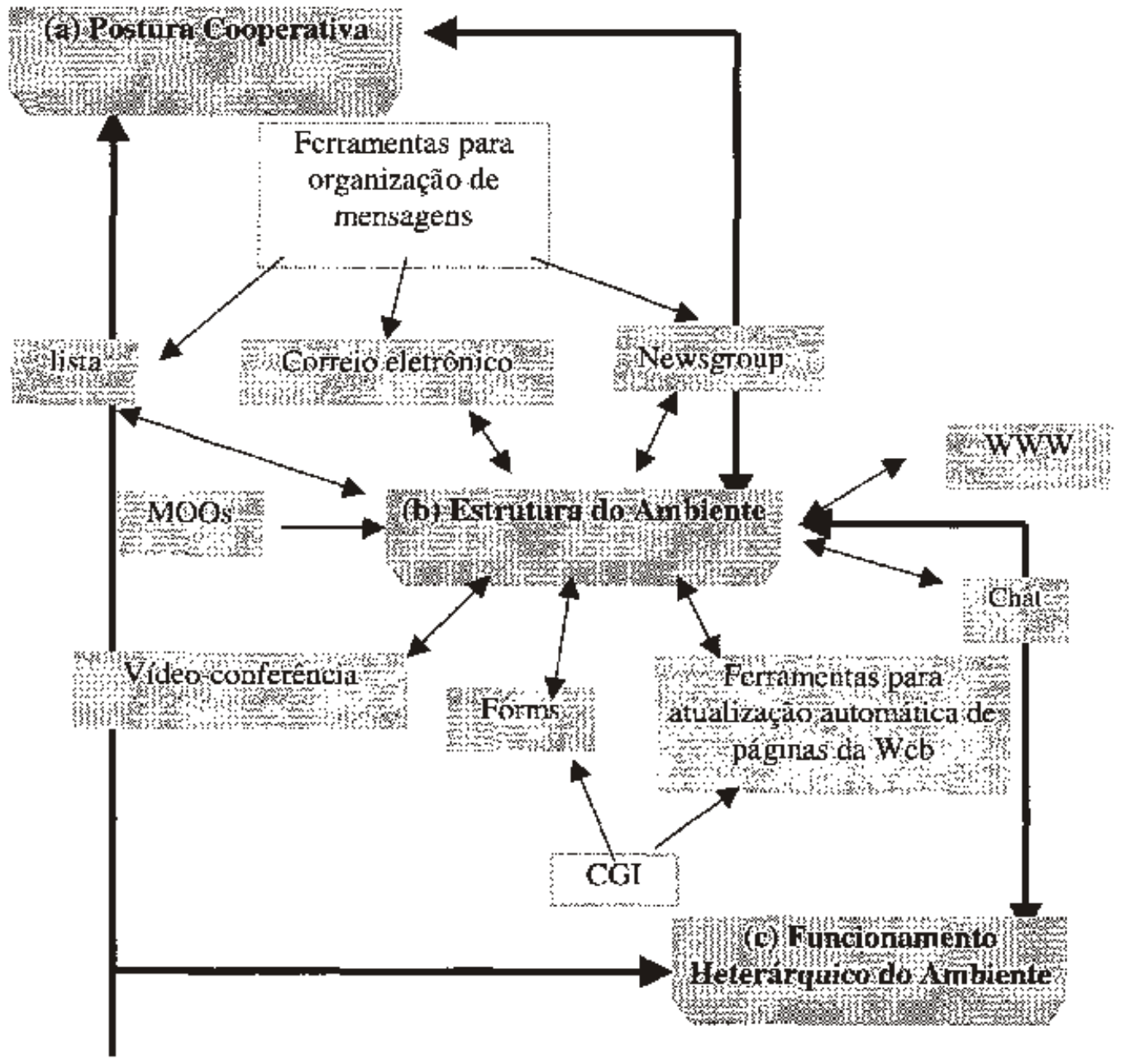

Figura 8: Estrutura do Ambiente

O correio eletrônico é a ferramenta para comunicaçăo à distância via rede de computadores mais utilizada e difundida. É importante que cada um dos participantes da cooperaçäo tenha um endereço eletrônico próprio, pois ele representa um canal permanente e personalizado de comunicaçao, onde cada um pode contribuir com autonomia e responsabilidade. Este recurso permite a interaçán assíncrona do tipo "um para um", "um para todos" e "todos para todos". Para estes dois últimos utilizam-se as listas de discussōes que sāo formedas por um conjunto de pessoas que tem como objetivo a discussão de um determinado assunto.

A criação de uma lista é de suma importáncia tanto para que os participantes conheçam o.que o pensamento dos parceiros quanto para expressarem suas opiniōes. Outra possivel funçăo das listas e o armazenamento das interaçŏ́es, o quọ toma viávẹl uma avaliaçăo individual e do grupo com base na evoluçáa dos registros.

O Newsgroup é também um serviço que permite a discussăo de assuntos por grupos de interesses. A diferença básica entre listas de discussōes e newsgroups é que em uma lista o usuário recebe todas as 
mensagens eriviadas, enquanto que no news as mensagens ficam armazenadas no servidor e o usuário só recebe as que selecionar.

Os usuários de tais serviços, poderiam beneficiar-se de ferramentes para a organizaçăo de mensagens recebidas e enviadas através do Correio Eletrónico (listas de discussōes e Newsgroups). Alguns produtos tem sido desenvolvidos nessa direçäo, embora esta tarefa nảo seja nada fácil pois implica numa análise textual das mensagens que diz respeito ao significado e năo somente a identifjoaçáo de freqüēncias, ou seja envolve uma análise semántica.

Os MOOs (Multiple Object Oriented) săo ambientes virtuais nos quais múltiplos usuário podem conectar-se a um servidor e interagir entre si e com o ambiente. Esse ambiente contem salas criadas pelos usuârios. Tais salas e os objetos "colocados" nelas säo descritos textualmente de forma a representarem o local onde a conversaçäo está ocorrendo. O MOO possibilita tanto a conversaçäo privada entre duas ou mais pessoas como uma comunicaçăo aberta onde todos que estäo na sala se comunicam (DILLEMBOURG, 1996). Os individuos que interagem neste ambiente se consideram uma comunidade, onde as pessoas tem diferentes papéis, direitos e responsabilidades. Existe a figura do wizard, programmer, player e guest. Conforme o interesse, a freqü̈ñncia de uso e comportamento do indivíduo ocorre mudanças de status nessa comunidade virtual. Chat $e$ um recurso gráfico que possibilita a conversa de diwersas pessoas, näo requerendo a identificaçäo das mesmas. Os chat sảo amplamente divuigadas em páginas da WWW e sāo organizados em salas geralmente classificadas por assuntos ou por idade.

A diferença entre os MOO e os chats, \& que o primeiro é um ambiente textual utilizado predominantemente ho meio universitário, enquanto que o segundo é quase que em sua totalidade grafico e năo existem nlveis hierárquicos entre os usuários.

Outras diferenças de utilização do MOO emr relação ao Chat são: identificação dos usuários, ou seja, para conectar-se ao MOO é necessário a utilizaçāo de urma senha;

funcionamento em máquinas bastante simples;

possibilidade de disponibilizar materiais que podem ser acessados;

privacidade, isto é, tanto as conversas quanto os materiais podem ser restritos apenas ao grupo: existência de um espaço onde ficam amazenados recados para os usuários.

As teleconferéncias, como seu nome sugere, säo conferéncias que envolverm usuários fisicamente distantes, podendo envolver a transmissăo e recebimento de texto, som (audioconferência) ou imagem (videoconferência), ou ainda a combinaçāo destes. Atualmente a comunicação que predomina e sincrona, podendo ser "um para todos" ou "todos para todos", dependendo do objetivo a ser alcançado e da sua metodologia.

Os Forms são formulários elaborados e expostos em paginas da WWW, para serem preenchidos pelos "visitantes" destas. As respostas podem ser enviadas para um ou mais endereços eletrónicos ou para o endereço de uma servidor que o gerenciará. Seu propósito em um ambiente cooperativo nāo é somente estabelecer uma interaçäo entre o(s) "construtor(es)" e o(s) "visitante(s)" de sites mas também a construçāo conjunta dos mesmos. Geralmente a interaçäo ocorre de forma assíncrona e "um para um", existindo porérr a possibilidade do usuário tomar sua contribuiçăo disponivel automática o instantaneamente, quendo sāo utilizadas no site ferramentas para atualizaçăo constante e automáticas de páginas da Web. Um exemplo e a utilizaçāo de programas em CGI (Common Gateway Interface).

A WWW í um ambiente gräico hipertextual que disponibiliza recursos multimídia alem de integrar os seniços e recursos descritos acima. Atraves da Web pode-se criar e organizar sites interativos, utilizar softwares de co-gutoria, compartilhar conhecimentos e informaçóes interligando-se a vários lugares remotos formando uma verdadeira "teia" de conhecimento, informaçäo e interaçăo entre indivíduos e recursos, facilitando a construção de ambientes cooperativos.

Conforme LÉVY (1996) a Web permite a criaçăo coletwa da inteligénçia, o advento da rede faz com que o computador deixe de ser um centro, e tome-se um fragmento da trama, um componente incompleto da rede universal. Através dela, milhōes de pessoas e de instituiçōes trabalham na construção e na disposição do imenso hipertexto da World Wide Web. Năo é apenas uma casta de especialistas mas a grande massa das pessoas săo levadas a aprender e produzir conhecimento de manaira colaborativa em sua atividade cotidiana. 
c.Funcionamento Heterárqulco do Ambiente: um ambiente de aprendizagem requer um certo "funcionamento". Com a finalidade de alcançar o funcionamento heterárquico, as autoras propöem alguns aspectos/elementos necessários, conforme a figura abaixo:

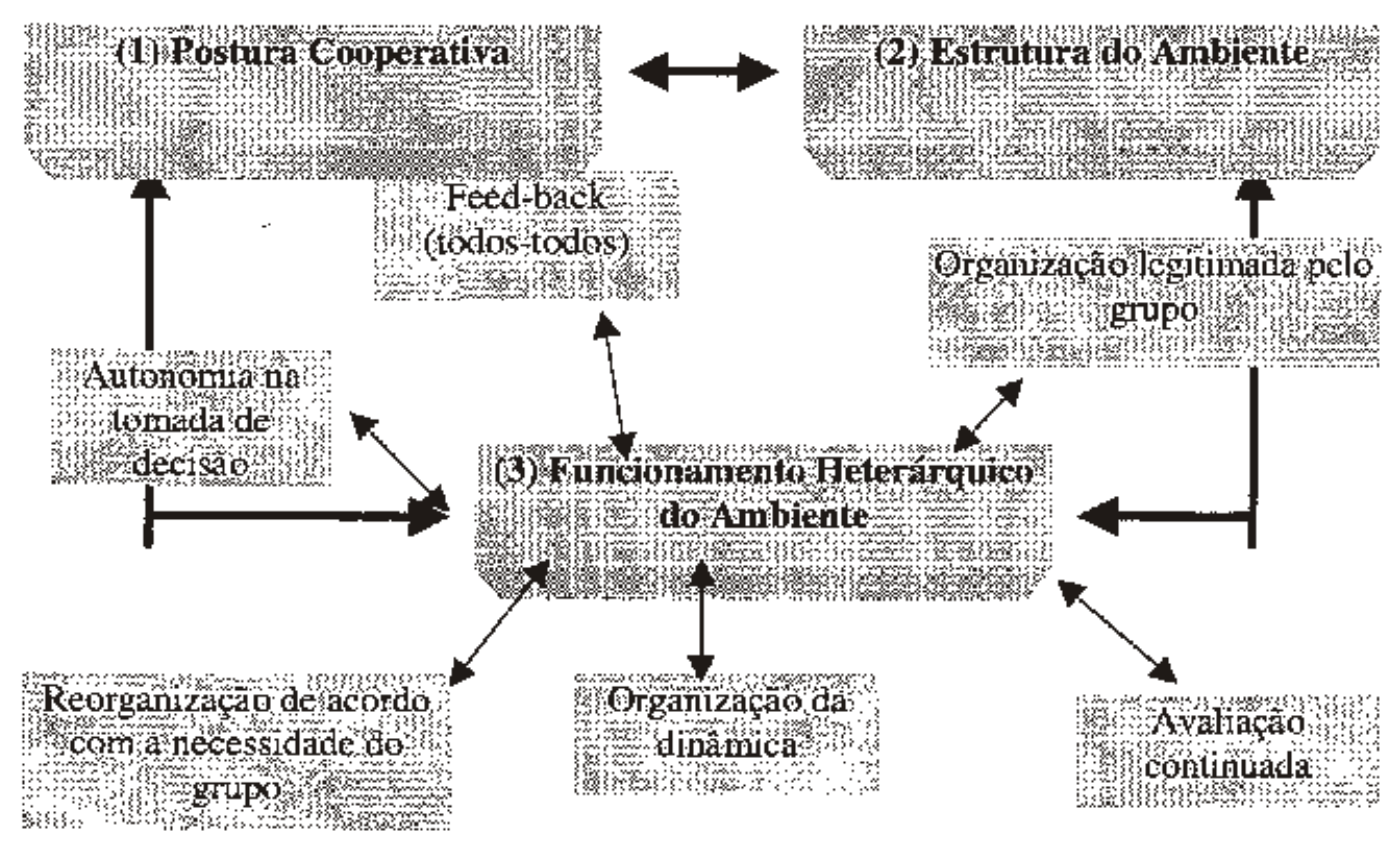

Figura 9: Funcionamento Heterárquico do Ambiente

Toda tomada de decisão num ambiente de aprendizagem cooperativo leva implíito um consenso de grupo onde cada indivíduo que o constitui é autônomo na sua contribuiçāo. Mas, tais contribuiçōes só se tornam legitimas quando todos (ou a maioria) os integrantes do grupo estiverem de acordo. Asssim, D "funcionamento" que as autoras propōem năo é aquele realizado por apenas uma ou poucas pessoas que tenham o papel de coordenar ou dirigir as interaçöes, como tem-se observado em experièncias de EAD via redes de computador. Tais papéis ou funçōes poderäo vir a existir mas somente se e quando o grupo assim o achar conveniente.

Em um ambiente onde nāo se tem normas previamente definidas, rígidas e impostas faz-se necessário a organização e reorganização da dinâmica do ambiente, no que tange a objetivos, metas, papéis e estrutura f́sica de acordo com as necessidades emergentes do grupo. Para tanto, avaliar e fornecer feedback continuamente se faz necessário pois permite verificar as falhas, os pontos fortes $\mathrm{e}$ fracos, e repensar a organiżaçăo do ambiente cooperativo.

\section{Consideraçóes Finais}

Várias sāo as tentativas para uma aprendizagem em ambientes cooperativos na internet. Percebese a interaçăo, a colaboraçào e a cooperaçăo entre indivíduos camo aspectos essenciais para os processos de construçăo e reconstrução do conhecimento e crescimento pessoal. Através deles é possivel a descentração, a reflexăo, a coordenaçăo, a organizaçăo de idéias para atingir um novo estágio de equilíbrio ampliando a autonomia tanto a nível individual como coletivo.

A Internet possibilita a "democratizaçăa", a interação e a rapidez de acesso z̀ intormação porém, sua maior contribuição ainda está por vir e diz respeito ao relacionamento interpessoal que aumentará tanto quantitativa quanto qualitativamente, devido à possibilidade de aproximaçăo entre pessoas e a criação de uma nova "cultura" de crescimento com o outro em qualquer área de atuaçāo.

O atual contexto social, económico e tecnológico coloca os individuos e as organizaçóes perante problemas complexos, que requerem uma aproximação entre diferentes parceiros, de forma a solucionar probiemas comuns e explorar oporturidades conjuntas. A tecnologia pode ser um elemento-chave para viabilizar este novo tipo de relacionamento. 
As instituições de ensino podem incorporar em sua prática concepções de colaboraçăo e cooperaçăo associadas ao ambiente telemático, não bastando porém se apropriar de ferramentas interativas telemáticas para apenas reproduzir o modelo tradicional de ensino. Isto seria subutilizar o enorme potencial destes novos recursos.

O desafio é compreender que o sucesso depende da eficaz utilizaçăo das tecnologias da informação e comunicaçāo, acompanhada de uma mudança de postura e de atitude quanto ao modo de realizaçăo das atividades.

Considerando que as futuras geraçōes precisarāo cada vez mais de uma educação continuada, devido as rápidas transformaçōes sociais e tecrológicas, deve-se realizar esforços para a formação de cidadãos frente a um contexto tão rico e sempre mutante de informaçōes, capazes de serem ativos, críticos e criativos e que utilizem as novas tecnologias de comunicaçăo de formas interativa, colaborativa e cooperative visando uma sociedade mais humanizada.

Isso constitui-se, talvez, o maior desafio das instituiçōes de ensino na construçāo das novas lideranças para atuaçăo num novo mundo que se vislumbra com a virada do século. É possivel que as instituiçōes de ensino consigam com esses novos recursos e com esse novo paradigma, concepçōes e idéias aqui trazidas alcançar/viabilizar um ambiente de aprendizagem cooperativo, que com a estrutura até entăo existente apenas ficou como ideal näo concretizado.

\section{Referências Bibliográficas}

BARRROS, L.A. Suporte a Ambientes Diatribuidos para Aprendizagem Cooperativa, 1994. (Tese de Doutoraco)

CLERMONT-PERRET, ANNE-NELLY "Transmitindo Conhecimentos; negociaçōes implicitas no relacionamento professor-estudante" In: Oser, Fritz, K; Dick, Andreas; Patry, Jean-Luc (ed) Effective and Responsibie Teaching the New Synthesia. Săo Francisco: Jossey-Bass, 1992.

COSTA, A. R. Interaçōes interindividuais em Flede Telemática. Anais do VIl Congresso Internacional Logo e I Congresso de Informatlca Educativa do Mercosul. Porto Alegre: Palloti, 1995.

DILLEMBOURG P. Miscommunication in Multi-modal Collaboration. AAAI Workshop on Detecting Repairlng, And Preventing Human-Machlne Miscommunication, 1996.

ECHEITA, G. E MAFTIN, E. Interação Social e Aprendizagem In: Coll, Cesar e outros. Desenvolvimento Psicológlco e Educacäo, vol 3, Porto Alegre: Artes Médicas, 1995,

GARNIER, C; BEDNARZ N. E VLANOVSKAYA J. Após Vygotsky e Piaget: Perspectiva Social e ConstrutivistaEscola Russa e Ocidental, Porto Alegre: Artes Médicas, 1996.

LEVASSEUR, ROBERT E. People Skilts: Lauching a Cooperative Learning Team.. Interfaces 26: 6 NovemberDecember, 1996.

LÉVY, P. O que é o virtual? Săo Paulo: Editora 34, 1996.

FELLERS, J.W. People Skilss: Using the Cooperative Learning Model to Teacch Students "People Skills'. Interfaces, vol. 26, seplember-october, 1996.

RAMOS, E. M. Análise Ergonómica da Sistema HiperNet Buscando o Aprendizado da Cooperaçăo e da Autonomia (tese de Doutoraco), Fionaantópolis, 1996.

RIEL, M. A Internet: uma terra para ser Fundada mais que um oceano para ser Surfado, httpi/t

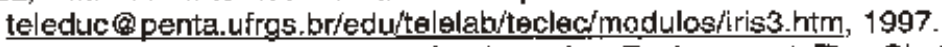

SCHRUM, $L$. Creating Collaborative Learning EnvironmentsThe Challenge for Distant Learners. Proceedings of EDMEDIA 97 \& ED-TELECOM 97-World Conference on Educational Multimedia and Hypermedla \& World Conference on Educational Telecommunlcatlons__Calgary, Alberta, Canada; June 14-19, 1997.

THORNBURG. D. D 2020 Visóes para o Futuro da Educação. http://www.tcpd.org, 1997

ULINE, C. L. Knowledge in the Information Age: Effortless Communication and the Effort of Refiective Thought. Educational Technology, sept/oct, 1996

VYGOTSKY, E.V. Pensamento e Linguagem. São Paulo: Martins Fontes Editora, Ltda, 1987. 